\title{
Neurophysiological Study of Traumatic Brain Injury: To Slice or Not to Slice
}

\author{
Jianli Sun and Kimberle M Jacobs* \\ Department of Anatomy \& Neurobiology, Virginia Commonwealth University, USA
}

Submission: March 04, 2017; Published: March 20, 2017

*Corresponding author: Kimberle M Jacobs, PhD Associate Professor, Department of Anatomy \& Neurobiology Virginia Commonwealth University, PO Box 980709 Richmond, VA 23298, USA, Tel: 804-827-2135; Fax: 804-828-9477; Email: kmjacobs@vcu.edu

\begin{abstract}
Diffuse axotomy is characteristic of mild traumatic brain injury (TBI) both clinically and in experimental models. Axotomy also occurs during preparation of acute brain slices for physiological recordings. Brain slices have been used for decades and have many advantages, including the ability to select cells within particular locations or with specific morphologies for study. The question addressed here is whether creating additional axotomy by preparing brain slices introduces additional injury that is already typical of TBI. We have previously demonstrated alterations in both intrinsic membrane and synaptic properties recorded in brain slices after mTBI. Here we examined whether axotomized neurons differ from intact neurons in slices made from naïve mouse pups. There was no significant difference in either excitatory synaptic postsynaptic currents or in any measures of intrinsic membrane and cellular properties. These results suggest that creating the brain slices does not induce alterations similar to that observed within two days of mTBI induced by fluid percussion injury. Thus ex vivo slices are an appropriate methodology to study the effects of TBI.
\end{abstract}

Keywords: Ex vivo slice; Electrophysiology; Axotomy; EPSC; Membrane properties; Neurotrauma

Abbreviations: AHP: After Hyperpolarization; APP: Amyloid Precursor Protein; DAI: Diffuse Axonal Injury; DAP: Depolarizing After Potential; DTI: Diffusion Tensor Imaging; TBI: Traumatic Brain Injury

\section{Introduction}

One of the most critical neuropathological features of traumatic brain injury (TBI) is axotomy [1-5]. Even in mild (m) TBI, diffuse axotomy is easily and consistently observed as axons that end in swellings and dislocation from the distal part of the axon [6-8]. Integrity of axons can be measured in the clinical population with diffusion tensor imaging (DTI) [9-12]. Patient outcome has been correlated with DTI results, [13-16] although subacute imaging may be most effective in this regard $[17,18]$. Correlations may also be stronger for severe and moderate as opposed to mild injuries [19]. DTI results have also been shown to correlate with the degree of diffuse axonal injury (DAI) as measured with amyloid precursor protein (APP) staining that accumulates in the axonal swelling $[20,21]$. Treatment assessments have typically been focused on reduction of this axonal injury [22-29], although it has also been recognized that some measures of DAI improve over time while cognitive dysfunction persists [30].

Because axotomy also occurs during preparation of ex vivo brain slices, it could be argued that this methodology should not be used for study of mechanisms associated with TBI. Vibratome-axotomized neurons can certainly be identified at the surface of acute slices (Figure 1A \& 1B). This is one reason most investigators performing recordings in slices choose neurons that are at least one cell layer deep to surface neurons, and typically 40-60 m into the tissue. Creation of ex vivo slices for study of normal physiological function has been a staple of neuroscience research for decades [31,32]. The benefits of stability, visualized access to specific cell types and placement of electrodes, as well as feasibility of drug application have been previously described [33-35]. However, the idea that slicing produces pathology has also been used to create a model of post-traumatic epilepsy utilizing organotypic hippocampal slices that survive for weeks [36-40]. In this model, interictallike epileptiform activity is first observed after 14 days in vitro, while ictal-like activity is seen by 21 days [38]. The fact that this abnormal activity develops in days and not hours suggests that it may be due to synaptic reorganization that is secondary to the axotomy and thus unlikely to play a role in the physiology of acute slices.

We recently chose to use the acute slice to study physiological effects of trauma, specifically in order to target the axotomized neurons which are in the minority and located diffusely within 


\section{Open Access Journal of Neurology \& Neurosurgery}

the cortex after a mild injury, [6,41-43]. Identification of the neuron as either axotomized or intact prior to the recording was made simple by the use of YFP-h mice, in which YFP is localized to a subset of layer $V$ pyramidal neurons [44]. The ability to identify the status of the axon prior to the recording is a benefit over post-recording attempts to identify dye-filled neurons, which can have a low recovery rate [45]. In our studies a mild central fluid percussion injury was performed and acute slices were made 1 or 2 days after injury or sham-injury or in age-matched naïve mice. Care was taken to create coronal sections by blocking the brain with a brain slicer matrix (Zivic Instruments). While even a coronal block can still produce transection of dendrites or axons for neurons within rostral parts of the cortex, in our TBI studies, neurons selected for recordings were more caudally located, within somatosensory cortex.
In addition, chosen neurons were deep to the surface and thus were not vibratome-axotomized. Despite the initial focus on TBI-axotomized neurons, we found that in traumatized brain, pyramidal neurons with axons intact to the subcortical white matter also differed from control neurons. Although both intact and axotomized neurons of the injured brains were different from non-injured controls, their time course and properties were often also different from each other [46,47]. We suggest that this may be due to feedback selectively from the intact neurons that may then influence homeostatic processes [47]. Because intact neurons of the injured brain were different from intact neurons of the control brain, this suggests that the injury is at least creating additional abnormalities to any that might be induced by vibratome slicing.

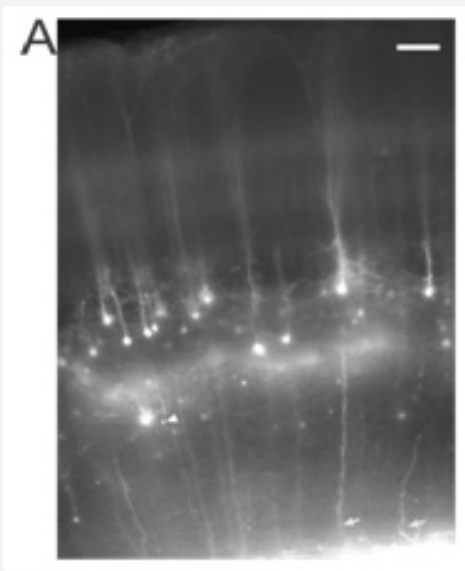

B
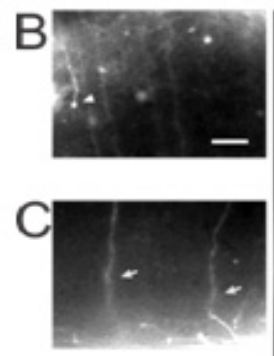

$\mathrm{D}$
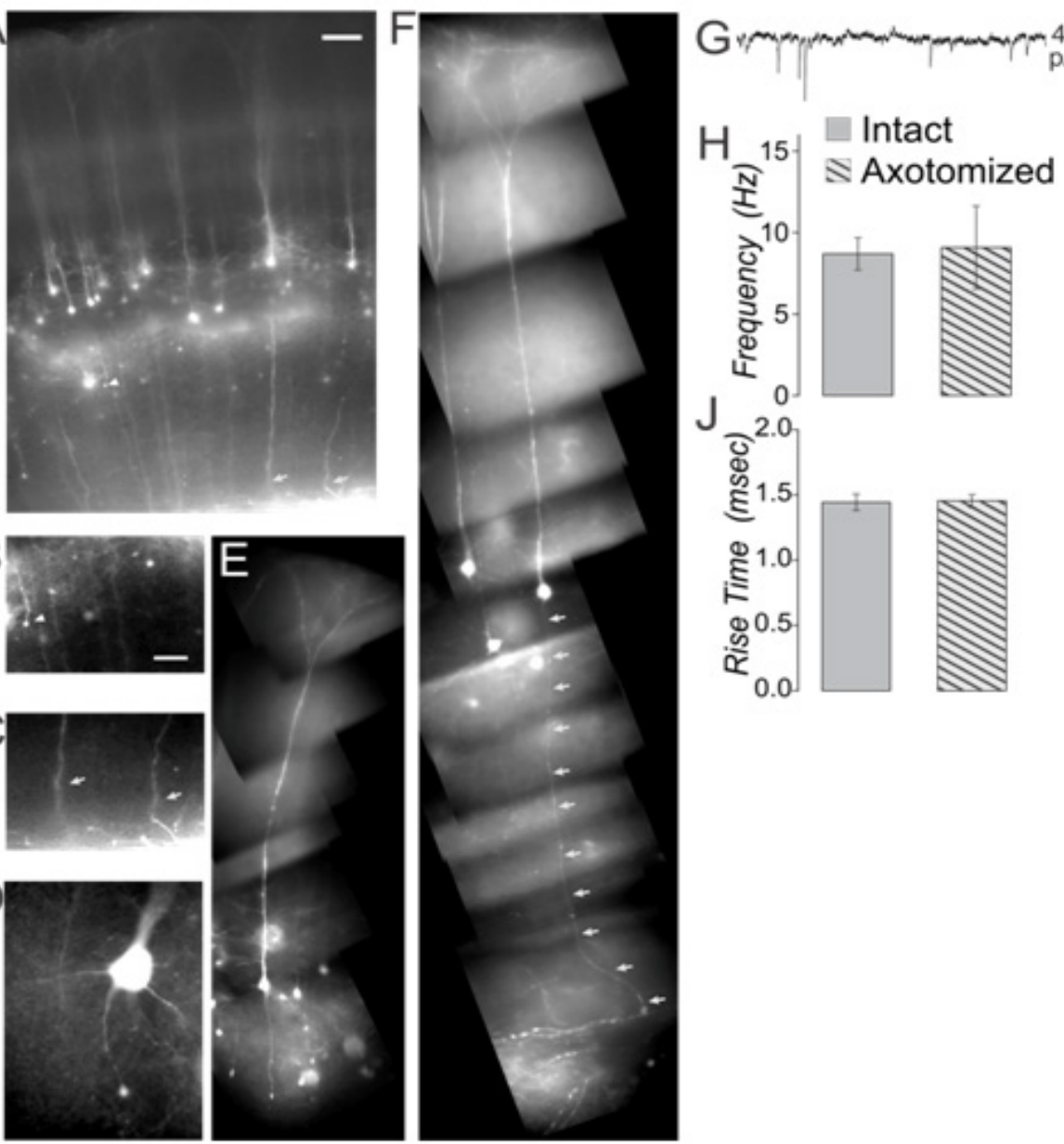

$J$
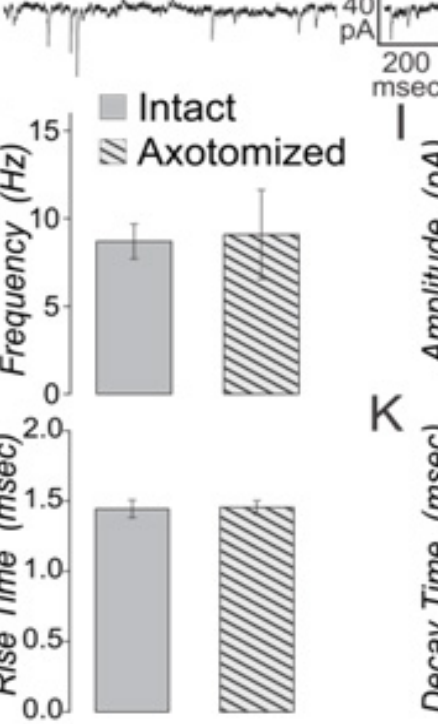

\section{0}

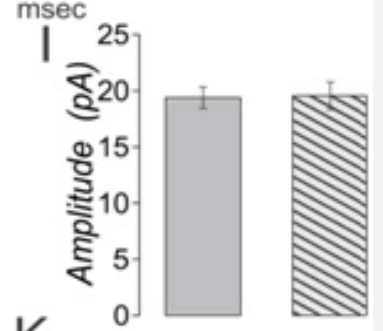

K
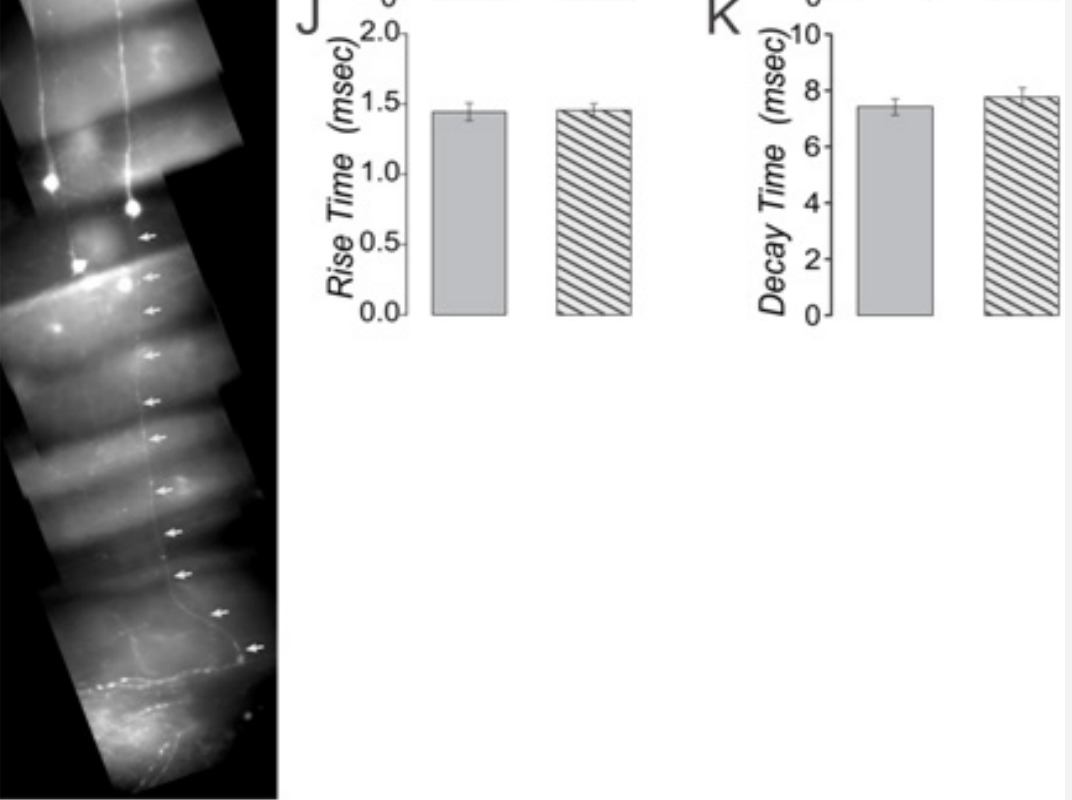

0

Figure 1: Axotomized and intact layer $V$ pyramidal neurons after creation of coronal brain slices from naive YFP-h mice. A) Image of YFPlabeled pyramidal neurons taken during from live slice. Both axotomized (white arrowhead) and intact neurons (gray arrow) can be seen in the same slices. Scale bar $=0.1 \mathrm{~mm}$. B) Axon severed at white arrowhead (same as in A). Scale bar for B and C $=0.05 \mathrm{~mm}$. C) Intact axons projecting into subcortical white matter from gray arrows in A. D-F) Images from confocal microscope of slices ixed and mounted after recordings. D) Example of a layer $\vee$ pyramidal neuron axotomized near soma as indicated by axonal swelling. Scale bar $=0.01 \mathrm{~mm}$. E) Example of axotomy at a more distant site from soma. Scale bar in $E=0.03 \mathrm{~mm}$ for $E$ and 0.019 for $F$. F) Example of pyramidal neuron with apical dendrite projecting to layer I and axon projecting to and turning and following subcortical white matter. G) Spontaneous EPSCs recorded from an intact (left) and vibratome-axotomized (right) neuron. For each cell, the frequency (I), amplitude (J), rise time (K) and decay time (L) of sEPSCs was measured. These values were not different for intact compared to axotomized neurons from naive brain ( $N$ $=14$ and 15 neurons, respectively). 

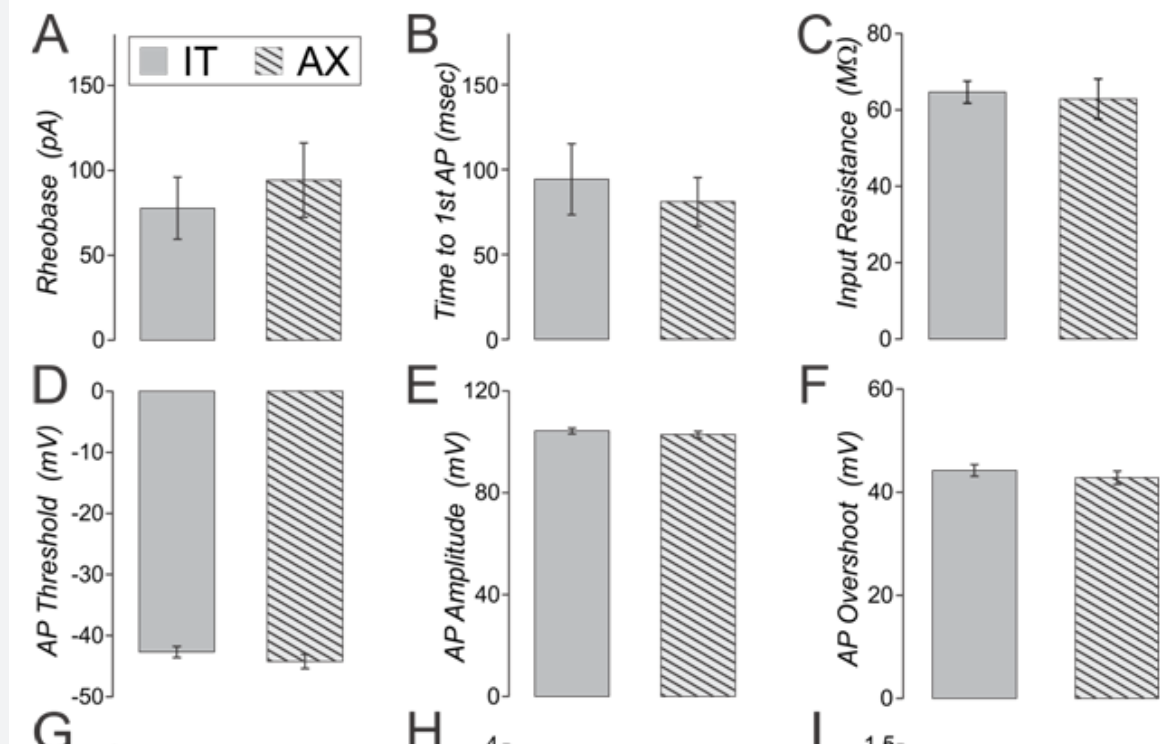

F
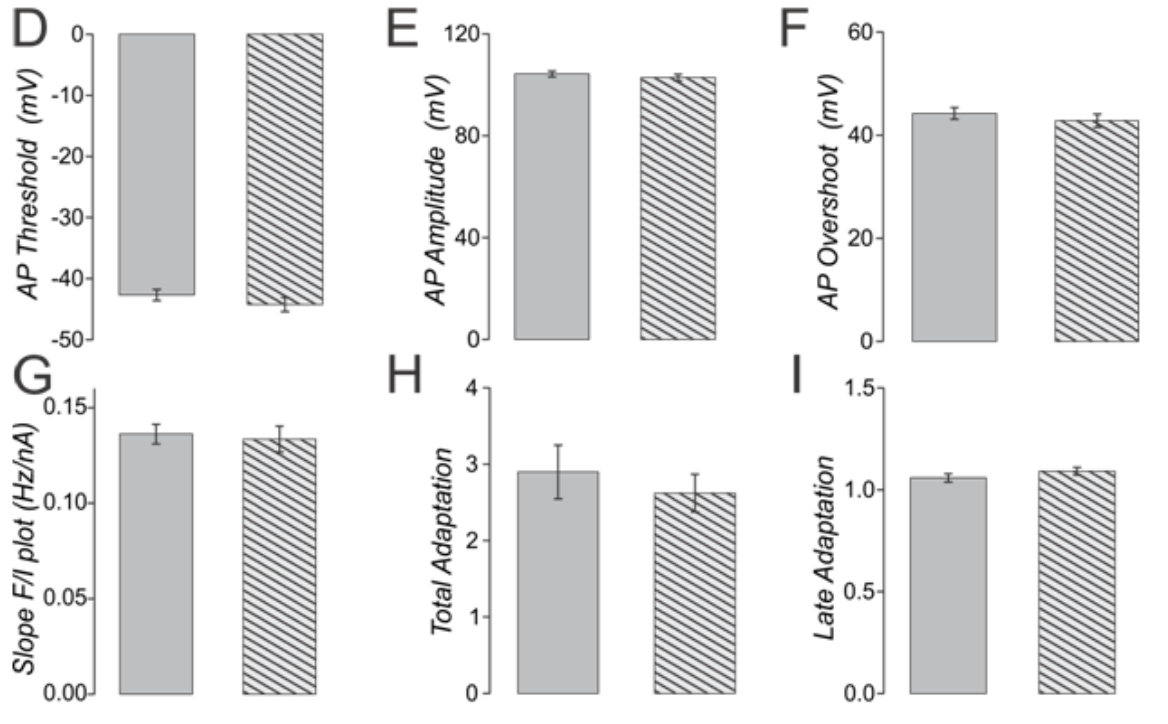

I 1.5
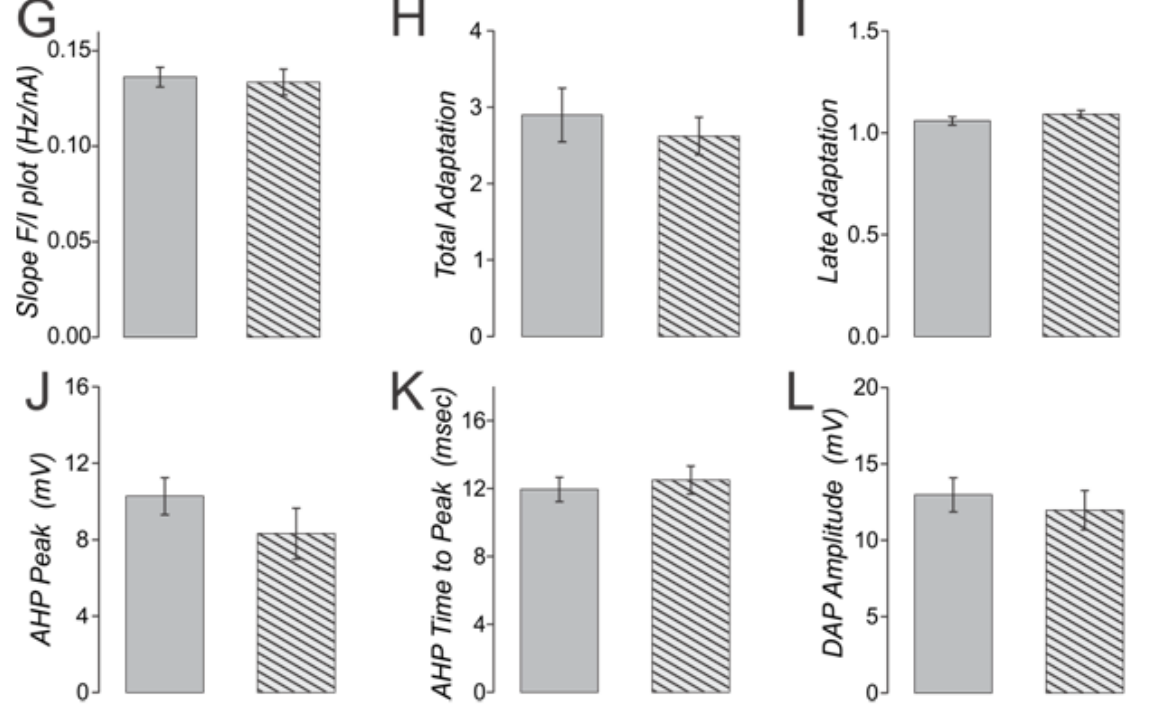

Figure 2: Comparison of intrinsic properties for intact (solid gray) and axotomized (diagonal black stripe) layer $V$ pyramidal neurons. There is no signi icant difference on any measure for these two groups (t-tests, $p>0.05, \mathrm{~N}=13$ intact and 14 axotomized neurons for all measures except Slope F/l plot, AHP peak, and AHP Time to Peak, where only RS non-doublet cells were included in the analysis and $N=10$ intact and 11 axotomized neurons).

If axotomy due to vibratome slicing does indeed alter cellular properties within the 6-8 hours of recording time after preparation, then these properties would be expected to differ between intact and vibratome-axotomized neurons in cortex from naïve mice. Slices prepared from YFP-h mice were used to test this idea. Here again we made careful coronal blocks using the brain slicer matrix. When done with brains from naïve mice, this results in the majority of the layer $\mathrm{V}$ pyramidal neurons within primary somatosensory cortex having both axons that can be followed to the subcortical white matter and dendrites that can be followed to their natural termination in superficial layers (Figure 1A). Near the surface of the living slice, some vibratome-axotomized neurons can also be seen (Figure 1B) in the same slices from which intact neurons are also present
(Figure 1C). Axotomy can occur both near the soma (Figure 1D) and several hundred microns distant (Figure 1E).

Whole cell patch clamp recordings were made from axotomized and intact layer $\mathrm{V}$ pyramidal neurons from the same slice, using previously described methods [46,47]. Spontaneous (s-) EPSCs did not differ in frequency, amplitude, rise time nor decay time between intact and axotomized neurons from naïve brain (Figure $1 \mathrm{G}-\mathrm{K}$, t-tests, $\mathrm{p}>0.05$ for 14 intact and 15 axotomized neurons). A series of hyperpolarizing and depolarizing step currents $(400 \mathrm{msec},-200$ to $490 \mathrm{pA}$ in $10 \mathrm{pA}$ steps) was applied to assess intrinsic properties [33]. We have previously shown that the YFP-labeled population in these mice consists of some neurons with intrinsically-bursting (Figure IB) and some with regular-spiking (RS) firing patterns [33]. Here we 
found that again both of these firing patterns were observed in axotomized as well as intact neurons (IB were: 2 of 15 intact and 3 of 17 axotomized neurons). For other intrinsic measures, only the RS neurons were considered (in all cases t-tests were used to compare intact and axotomized groups with significance set to $\mathrm{p}<0.05$ ). The lowest current to produce an action potential (rheobase) was not different for intact compared to axotomized neurons in slices from naïve animals (Figure 2A). The time to the first action potential at rheobase, and the input resistance were also not significantly different between these two groups (Figure 2B \& 2C).

A home-written java program was used to automatically detect every action potential, after-hyperpolarization (AHP) and depolarizing-after-potential (DAP) recorded from each neuron in the depolarization step series. Measures were then averaged for all action potentials or AHPs or DAPs recorded from that neuron (typically several hundred action potentials per neuron). Action potential threshold was measured as the interpolated membrane potential at which the first derivative of the membrane potential crossed the threshold of $10 \mathrm{~V} / \mathrm{s}$. Total adaptation was measured as the frequency of the first two action potentials divided by the frequency of the last two action potentials responding to the $400 \mathrm{msec}$ long depolarizing step current. Late adaptation was measured as the frequency of the 4 th and 5 th action potential divided by the frequency of the last two action potentials. For both total and late adaptation measurements were only made in sweeps with 8 or more action potentials. Nine measures of action potential, AHP and DAP characteristics are shown (Figure 2D-2L). None of these were significantly different in intact compared to vibratome-axotomized neurons recorded in slices from naïve brain. Also on more than 100 additional measures including action potential halfwidth, rise and decay time, there was no significant difference between these groups. When these same measures are examined in sham-injured YFP-h mice, there is also no significant difference between axotomized and intact neurons on any of these measures (Sun \& Jacobs, unpublished observations). When these same synaptic and intrinsic property measures are examined in naïve cyclophilin-D knockout mice or separately in sham-injured cyclophilin-D knockout mice, there is also no difference between vibratome-axotomized and intact neurons (Sun \& Jacobs, unpublished observations). These findings suggest that the abnormalities previously observed after trauma are not induced by the creation of brain slices.

Certainly any experimental preparation and even the act of observing will have some effect on the observations [48-50]. Under conditions of normal artificial cerebrospinal fluid (aCSF) that baths the slices, it is well known that neuronal activity is reduced compared to that observed in vivo even under anesthesia [51]. The best ionic composition of the slicing solution and aCSF, as well as the best chamber conditions for maintaining slice health continue to be sought $[32,34]$. While some axotomy in the preparation of cortical slices cannot be eliminated, the effects of it on the data can be reduced by making coronal slices, choosing sections that are posterior enough to have layer $\mathrm{V}$ pyramidal neurons with dendrites reaching the pia and axons reaching the white matter, and recording from neurons deep to the slice surface. Under all of these conditions, only after TBI are axotomized neurons observed deep to the slice surface. In the YFP-h mice, the axotomized and intact neurons appear in live slices similar to those observed in sections made after fixation of the intact brain (compare Figure 1 here to Figure 1 of Greer 20116). We conclude that acute ex vivo slices are valid and useful for characterizing cellular physiological abnormalities in the study of TBI.

\section{Acknowledgement}

This work was supported by NIH Grant NS077675. We thank Anders Hånell for help developing the Java analysis program.

\section{References}

1. Johnson VE, Stewart W, Smith DH (2013) Axonal pathology in traumatic brain injury. Exp Neurol 246: 35-43.

2. Chung RS, Staal JA, Mc Cormack GH, Dickson TC, Cozens MA, et al. (2005) Mild axonal stretch injury in vitro induces a progressive series of neuro filament alterations ultimately leading to delayed axotomy. J Neurotrauma 22(10): 1081-1091.

3. Maxwell WL, Povlishock JT, Graham DL (1997) A mechanistic analysis of non disruptive axonal injury: a review. J Neurotrauma 14(7): 419440.

4. McKee AC, Stein TD, Kiernan PT, Alvarez VE (2015) The neuropathology of chronic traumatic encephalopathy. Brain Pathol 25(3): 350-364.

5. Johnson VE, Stewart W, Smith DH (2013) Axonal Pathology in Traumatic Brain Injury. Experimental neurology 246: 35-43.

6. Greer JE, McGinn MJ, Povlishock JT (2011) Diffuse traumatic axonal injury in the mouse induces atrophy, c-Jun activation and axonal outgrowth in the axotomized neuronal population. J Neurosci 31(13): 5089-5105.

7. Christman CW, Grady MS, Walker SA, Holloway KL, Povlishock JT (1994) Ultra structural studies of diffuse axonal injury in humans. J Neurotrauma 11(2): 173-186.

8. Povlishock JT, Becker DP (1985) Fate of reactive axonal swellings induced by head injury. Lab Invest 52(5): 540-552.

9. Rowley HA, Grant PE, Roberts TP (1999) Diffusion MR imaging. Theory and applications. Neuroimaging clin N Am 9(2): 343-361.

10. Stroman PW, Bosma RL, Kornelsen J, Lawrence Dewar J, Wheeler Kingshott C, et al. (2012) Advanced MR imaging techniques and characterization of residual anatomy. Clin Neurol Neurosurg 114(5): 460-470.

11. Zappala G, Thiebaut de Schotten M, Eslinger PJ (2012) Traumatic brain injury and the frontal lobes: what can we gain with diffusion tensor imaging? Cortex 48(2): 156-165.

12. Mac Donald CL, Barber J, Andre J, Evans N, Panks C, et al. (2017) 5-Year imaging sequelae of concussive blast injury and relation to early clinical outcome. Neuroimage Clin 14: 371-378.

13. Paterakis K, Karantanas AH, Komnos A, Volikas Z (2000) Outcome of patients with diffuse axonal injury: the significance and prognostic value of MRI in the acute phase. J trauma 49(6): 1071-1075. 


\section{Open Access Journal of Neurology \& Neurosurgery}

14. Sharp DJ, Ham TE (2011) Investigating white matter injury after mild traumatic brain injury. Curr Opin Neurol 24(6): 558-563.

15. Kumar R, Husain M, Gupta RK, Hasan KM, Haris M, et al. (2009) Serial changes in the white matter diffusion tensor imaging metrics in moderate traumatic brain injury and correlation with neuro-cognitive function. J Neurotrauma 26(4): 481-495.

16. Genc S, Anderson V, Ryan NP, Malpas CB, Catroppa C, et al. (2017) Recovery of White Matter following Pediatric Traumatic Brain Injury Depends on Injury Severity. J Neurotrauma 34(4): 798-806.

17. Warner MA, Marquez dlP, Spence J, Wang JY, Harper C, et al. (2010) Assessing spatial relationships between axonal integrity, regional brain volumes, and neuropsychological outcomes after traumatic axonal injury. J Neurotrauma 27(12): 2121-2130.

18. Moen KG, Haberg AK, Skandsen T, Finnanger TG, Vik A (2014) A longitudinal magnetic resonance imaging study of the apparent diffusion coefficient values in corpus callosum during the first year after traumatic brain injury. J Neurotrauma 31(1): 56-63.

19. Moen KG, Brezova V, Skandsen T, Haberg AK, Folvik M, et al. (2014) Traumatic axonal injury: the prognostic value of lesion load in corpus callosum, brain stem, and thalamus in different magnetic resonance imaging sequences. J Neurotrauma 31(17): 1486-1496.

20. Mac Donald CL, Dikranian K, Song SK, Bayly PV, Holtzman DM, et al. (2007) Detection of traumatic axonal injury with diffusion tensor imaging in a mouse model of traumatic brain injury. Exp Neurol 205(1): 116-131.

21. Brody DL, Mac Donald CL, Shimony JS (2015) Current and future diagnostic tools for traumatic brain injury: CT, conventional MRI, and diffusion tensor imaging. Hand clin neurol 127: 267-275.

22. Dileonardi AM, Huh JW, Raghupathi R (2012) Differential effects of FK506 on structural and functional axonal deficits after diffuse brain injury in the immature rat. J Neuropathol Exp Neurol 71(11): 959-972.

23. Ma M, Li L, Wang X, Bull DL, Shofer FS, et al. (2012) Short-duration treatment with the calpain inhibitor MDL-28170 does not protect axonal transport in an in vivo model of traumatic axonal injury. J Neurotrauma 29(2): 445-451.

24. Rosomoff HL, Kochanek PM, Clark R, DeKosky ST, Ebmeyer U, Grenvik, et al. (1996) Resuscitation from severe brain trauma. Crit care med 24(2): S48-S56.

25. Koizumi H, Povlishock JT (1998) Posttraumatic hypothermia in the treatment of axonal damage in an animal model of traumatic axonal injury. J Neurosurg 89(2): 303-309.

26. Ma M, Matthews BT, Lampe JW, Meaney DF, Shofer FS et al. (2009) Immediate short-duration hypothermia provides long-term protection in an in vivo model of traumatic axonal injury. Exp Neurol 215(1): 119127

27. Donkin JJ, Cernak I, Blumbergs PC, Vink R (2011) A substance P antagonist reduces axonal injury and improves neurologic outcome when administered up to 12 hours after traumatic brain injury. J Neurotrauma 28(2): 217-224.

28. Park E, Bell JD, Baker AJ (2008) Traumatic brain injury: can the consequences be stopped? CMAJ 178(9): 1163-1170.

29. Graham DI, McIntosh TK, Maxwell WL, Nicoll JA (2000) Recent advances in neurotrauma. J Neuropathol Exp Neurol 59(8): 641-651.

30. Signoretti S, Vagnozzi R, Tavazzi B, Lazzarino G (2010) Biochemical and neurochemical sequelae following mild traumatic brain injury: summary of experimental data and clinical implications. Neurosurg Focus. 29(5): E1.
31. Aitken PG, Breese GR, Dudek FF, Edwards F, Espanol MT, et al. (1995) Preparative methods for brain slices: a discussion. J Neurosci Methods 59(1): 139-149.

32. Ting JT, Daigle TL, Chen Q, Feng G (2014) Acute brain slice methods for adult and aging animals: application of targeted patch clamp analysis and optogenetics. Methods Mol Biol 1183: 221-242.

33. Khurana S, Li WK (2013) Baptisms of fire or death knells for acuteslice physiology in the age of 'omics' and light? Rev Neurosci 24(5): 527-536.

34. Hajos N, Mody I (2009) Establishing a physiological environment for visualized in vitro brain slice recordings by increasing oxygen supply and modifying aCSF content. J Neurosci Methods 183(2): 107-113.

35. Dunwiddie T, Mueller A, Basile A (1983) The use of brain slices in central nervous system pharmacology. Fed Proc 42(12): 2891-2898.

36. Wahab A, Albus K, Gabriel S, Heinemann U (2010) In search of models of pharmacoresistant epilepsy. Epilepsia 51(3): 154-159.

37. Noraberg J, Poulsen FR, Blaabjerg M, Kristensen BW, Bonde C, et al. (2005) Organotypic hippocampal slice cultures for studies of brain damage, neuro protection and neurorepair. Curr Drug Targets CNS Neurol Disord 4(4): 435-452.

38. Dyhrfjeld Johnsen J, Berdichevsky Y, Swiercz W, Sabolek H, Staley KJ (2010) Interictal spikes precede ictal discharges in an organotypic hippocampal slice culture model of epileptogenesis. J Clin Neurophysiol 27(6): 418-424.

39. Mc Bain CJ, Boden P, Hill RG (1989) Rat hippocampal slices 'in vitro' display spontaneous epileptiform activity following long-term organotypic culture. J Neurosci Methods 27(1): 35-49.

40. Liu J, Saponjian Y, Mahoney MM, Staley KJ, Berdichevsky Y (2017) Epileptogenesis in organotypic hippocampal cultures has limited dependence on culture medium composition. PloS one 12(2): e0172677.

41. Reeves TM, Smith TL, Williamson JC, Phillips LL (2012) Unmyelinated axons show selective rostrocaudal pathology in the corpus callosum after traumatic brain injury. J Neuropathol Exp Neurol 71(3): 198-210.

42. Hanell A, Greer JE, Jacobs KM (2015) Increased Network Excitability Due to Altered Synaptic Inputs to Neocortical Layer V Intact and Axotomized Pyramidal Neurons after Mild Traumatic Brain Injury. J Neurotrauma 32(20): 1590-1598.

43. Vascak M, Jin X, Jacobs KM, Povlishock JT (2017) Mild Traumatic Brain Injury Disrupts Local Neocortical Inhibitory Structural Connectivity via Widespread Parvalbumin Interneuron Axonal Damage. Cereb Cortex in press 1-20.

44. Feng G, Mellor RH, Bernstein M, Keller PC, Nguyen QT, et al. (2000) Imaging neuronal subsets in transgenic mice expressing multiple spectral variants of GFP. Neuron 28(1): 41-51.

45. Tasker JG, Hoffman NW, Dudek FE (1991) Comparison of three intracellular markers for combined electrophysiological, morphological and immunohistochemical analyses. J Neurosci Methods 38(2-3): 129143.

46. Greer JE, Povlishock JT, Jacobs KM (2012) Electrophysiological abnormalities in both axotomized and nonaxotomized pyramidal neurons following mild traumatic brain injury. J Neurosci 32(19): 6682-6687.

47. Hanell A, Greer JE, Jacobs KM (2015) Increased Network Excitability Due to Altered Synaptic Inputs to Neocortical Layer V Intact and Axotomized Pyramidal Neurons after Mild Traumatic Brain Injury. J Neurotrauma 32(20): 1590-1598. 
48. Buks E, Schuster R, Heiblum M, Mahalu D, Umansky V (1998) Dephasing in electron interference by a 'which-path' detector. Nature 391: 871-874.

49. McCown TJ, Mueller RA, Breese GR (1983) Effects of anesthetics and electrical stimulation on nigrostriatal dopaminergic neurons. J Pharmacol Exp Ther 224(3): 489-493.
50. Alkire MT, Miller J (2005) General anesthesia and the neural correlates of consciousness. Prog Brain Res 150: 229-244.

51. Sanchez Vives MV, McCormick DA (2000) Cellular and network mechanisms of rhythmic recurrent activity in neocortex. Nat Neurosci 3(10): 1027-1034.

\section{Your next submission with Juniper Publishers will reach you the below assets}

- Quality Editorial service

- Swift Peer Review

- Reprints availability

- E-prints Service

- Manuscript Podcast for convenient understanding

- Global attainment for your research

- Manuscript accessibility in different formats

( Pdf, E-pub, Full Text, Audio)

- Unceasing customer service

Track the below URL for one-step submission https://juniperpublishers.com/online-submission.php 